\title{
FLORULA DA ILHA DE MOLEQUES DO SUL, SANTA CATARINA, BRASIL
}

\author{
ROGALSKI, L.D. \& ARAÚJO, A.C. \\ CTTMar, Universidade do Vale do Itajaí. Rua Uruguai, 458. Caixa Postal nº 360. \\ CEP. 88302 - 202 Itajaí-SC, Brasil
}

\begin{abstract}
Rogalski, L.D. \& Araújo, A.C. 2005. Flora of Moleques do Sul island, Santa Catarina, Brazil. Braz. J. Aquat. Sci. Technol. 9(1):45-48. ISSN 1808-7035. The floristic study of "Moleques do Sul" Island (Santa Catarina, Brazil), was carried out from May/2003 to September/2004. The collected material was dried and included at HLS herbarium (UNIVALI). Twenty-four species, congregated in 18 botanical families, have been identified. Fifteen new occurrences were registered for the island. Fabaceae was the best represented family. The species most widely distributed was Verbesina glabrata Hook. \& Arn. (Asteraceae).
\end{abstract}

Keywords: Floristic study, Moleques do Sul, Taxonomy

\section{INTRODUÇÃO}

O arquipélago de Moleques do Sul, formado por três ilhas, localiza-se $12 \mathrm{Km}$ ao sul de Florianópolis (SC - $27^{\circ} 51^{\prime}$ S e $48^{\circ} 26^{\prime} \mathrm{W}$ ), inserido no Parque Estadual da Serra do Tabuleiro. As ilhas, de formação granítica (Bege \& Pauli, 1988), apresentam dimensões variadas, e são de difícil acesso. A maior delas, onde foi realizado este estudo, possui $124 \mathrm{Km}^{2}$ e cerca de $100 \mathrm{~m}$ de altitude no topo, sem formações de praia.

Em 1988, foi realizado por Bege \& Pauli um estudo na ilha de Moleques do Sul no qual os autores se dedicaram a analisar as populações de aves que se utilizam da ilha para nidificar. No livro publicado referido acima, são apresentados aspectos sobre a ecologia, etologia, reprodução e dados do anilhamento de três espécies de aves marinhas: Sula leucogaster Boddaert (atobá marrom), Fregata magnificensis Mathews (fragata) e Sterna hirundinacea Lesson (trinta-réis-de-bicovermelho). Na pesquisa de Bege \& Pauli também foi realizado o levantamento da vegetação na ilha e apontada a importância da preservação das ilhas costeiras de Santa Catarina como abrigo para a fauna.

O uso da vegetação local para nidificação por algumas aves marinhas, como as já citadas acima e juntamente Larus dominicanus Lichtenstein (gaivotão), tem sido constatado em estudos recentes (Branco, 2003a, 2003b). Este arquipélago é considerado o principal sítio de reprodução das aves marinhas da costa catarinense (Branco, 2003a).

No estudo etológico das espécies de aves locais realizado por Bege \& Pauli, em 1988, houve também uma descrição da flora insular. Deste modo, criou-se a necessidade de se realizar um novo estudo florístico da ilha. O presente estudo, através da identificação e caracterização das espécies botânicas ali existentes, possibilita o conhecimento da flora insular atual de Moleques do Sul, e também contribui com estudos em áreas correlatas.

O levantamento florístico da maior ilha do arquipélago de Moleques do Sul fundamenta futuras ações para a conservação deste ambiente, assim como possíveis estudos a serem realizados que correlacionem as espécies vegetais insulares com seus representantes no continente.

\section{MATERIAL E MÉTODOS}

Para o levantamento e estudo da flora insular foram realizadas coletas mensais de espécimes floridos e/ou frutificados, durante os meses de maio/2003 a setembro/2004. Como o objeto de estudo tratava-se de uma pequena ilha, o método utilizado para todas as coletas foi percorrer toda a extensão da ilha coletando os espécimes. A fim de conservar o material botânico até a herborização em estufa, nos primeiros meses do estudo os vegetais eram coletados, mantidos em etanol $70 \%$ e acondicionados em sacos plásticos até serem postos na estufa, um ou dois dias depois da coleta; posteriormente, utilizou-se acondicionar o material apenas borrifado com água até a herborização em estufa, preservando-se melhor suas características. O processo de herborização foi encaminhado no Laboratório de 
Biologia Vegetal -Univali, de acordo com metodologia convencional em taxonomia (Instituto De Botânica, 1989).

As exsicatas - plantas desidratadas - resultantes foram incluídas na coleção do Herbário Lyman Smith (HLS - Univali). Cada coleção está acompanhada de uma ficha de identificação padrão, contendo dados referentes à data de coleta, ambiente e local da coleta, habitat, altura da planta, informações sobre o vegetal e outros dados ecológicos observados no momento da coleta que o coletor julgar relevantes e também a respectiva identificação, além de 2-3 duplicatas. Toda a coleção foi identificada através de chaves de identificação em literatura especializada até o nível taxonômico de espécie, sempre que possível (Barroso, G.M. 1978; Goldenber, A.; Smith, L.B. 1975; Kissmann, K.G.; 1993; Kissmann, K.G. \& Groth, D. 1993; Klein, R.M. 1979; Joly, 1998; Lombardo, A. 1984; Lorenzi, H. 1992 e 1998; Lorenzi, H .\& Souza, H.M. 2001; Miotto, S.T.S. 1999).

\section{RESULTADOS E DISCUSSÃO}

Neste levantamento florístico realizado na ilha de Moleques do Sul, foram identificados 24 táxons, reunidos em 18 famílias botânicas (Tabela 1). Dentre os táxons identificados, 15 são novas ocorrências para a ilha de Moleques do Sul, pelo fato de não terem sido citados no estudo realizado anteriormente por Bege \& Pauli (1988), e estão assinalados por asterisco na Tabela 1. Assim como há novas ocorrências para a ilha, existem também 18 táxons referidos no trabalho de Bege \& Pauli (1988) - que citou 31 - que não foram verificados no presente estudo.

As famílias mais representativas na ilha são Fabaceae e Poaceae, contendo três espécies cada. Uma espécie teve sua nomenclatura atualizada: Hippeastrum aulicum (Ker-Gawl) Herb., citado por Bege \& Pauli (1988) como Amaryllis aulica (Ker-Gawl) Herb., tem como nome atualmente aceito como sinônimo de $H$. aulicum. Em meio às novas ocorrências, encontramse Ipomoea cairica L. Sweet (Convolvulaceae), Tibouchina gracilis (Bonpl) Cogn. T. urvilleana (DC.) Cogn. (Melastomataceae), antes referidas para a ilha somente em nível genérico, foram identificadas em nível específico . Begonia cf. rupium (Begoniaceae) é outra importante novidade para a ilha, por se tratar de uma espécie endêmica do Estado de Santa Catarina (Smith \& Smith, 1971); portanto consideramos que a identificação desta espécie é de suma importância para valorizar a llha de Moleques do Sul como área de preservação tanto em relação à fauna quanto à flora.

É relevante a abundância fitofisionômica de Verbesina glabrata Hook. \& Arn. (Asteraceae), espé- cie arbustiva observada em grandes associações por toda a ilha. Tibouchina gracilis (Bonpl.) Cogn. e T. urvilleana (DC.) Cogn. (Melastomataceae), espécies subarbustivas, têm ocorrência também bastante expressiva no local.

Das espécies identificadas acredita-se que Phlox sp., $H$. aulicum e $H$. cf. robustus sejam espécies introduzidas como ornamentais. Phlox é um táxon norte-americano da família Polemoniaceae que reúne espécies ornamentais; no Estado de Santa Catarina, existem apenas duas espécies colecionadas, registradas no Herbário Barbosa Rodrigues HBR. Como a população encontrada na área de estudo não corresponde a nenhuma destas, trata-se de nova ocorrência do gênero registrada para Santa Catarina.

A ocorrência de espécies introduzidas foi citada por Bege \& Pauli (1988), porém não foram explicadas as causas e o seu modo de introdução na ilha. Portanto, a ocorrência de espécies ornamentais exóticas na Ilha de Moleques do Sul não é clara. Várias hipóteses podem ser levantadas, entre elas: o cultivo das mesmas em tempos remotos, dispersão anemocórica ou até mesmo pelas próprias aves que visitariam tanto a Ilha de Santa Catarina (Florianópolis) como também a Ilha de Moleques do Sul.

O baixo número de espécies encontrado na llha de Moleques do Sul em relação a outros ambientes insulares pode ser resultante de alguns fatores como: o perímetro reduzido, topografia acidentada, solo rochoso, a alta salinidade, a grande distância do continente - aproximadamente $12 \mathrm{Km}$-, e a influência dos ventos que castigam a paisagem constantemente.

\section{CONCLUSÕES}

Os dados obtidos através da identificação das coleções vegetais mostraram que a vegetação da llha de Moleques do Sul é heterogênea, por possuir representantes de muitas famílias botânicas e com variedade de habitats. Além disso, no período de coletas pôdese observar visualmente que os espécimes formam agrupamentos distintos, variando também a força dos ventos e a salinidade dependendo do local da ilha onde se encontram os espécimes.

A espécie mais abundante fitofisionomicamente na ilha é Verbesina glabrata Hook. \& Arn. (Asteraceae), observada em grandes associações por toda a ilha. Espécies ornamentais exóticas ocorrentes na ilha descaracterizam a vegetação nativa como flora original; sua existência no ambiente insular não é clara. Há grande possibilidade de as aves marinhas funcionarem como vetores de dispersão, incluindo na ilha espécies anteriormente não descritas para o local. 
Braz. J. Aquat. Sci. Technol., 2005, 9(1):45-48.

Tabela 1 - Listagem das espécies da flora da Ilha de Moleques do Sul

\begin{tabular}{|c|c|}
\hline Famílias & Espécies \\
\hline Acantaceae & Justicia brasiliana Roth. \\
\hline Amaryllidaceae & $\begin{array}{l}\text { Habranthus robustus Herb. ex Sweet } \\
\text { Hippeastrum aulicum (Ker-Gawl) Herb. }\end{array}$ \\
\hline Asteraceae & $\begin{array}{l}\text { Achyrocline satureoides (Lam.) DC* } \\
\text { Verbesina glabrata Hook. \& Arn. }\end{array}$ \\
\hline Begoniaceae & Begonia cf. rupium Irmscher* \\
\hline Blechnaceae & Blechnum serrulatum Rich.* \\
\hline Bombacaceae & Pseudobombax cf. grandiflorum (Cav.) A. Rob. ${ }^{*}$ \\
\hline & Chorisia cf. speciosa St. Hil. $\quad *$ \\
\hline Cactaceae & Pereskia aculeata Mill. \\
\hline Capparidaceae & Cleome rosea Vahl ex DC* \\
\hline Convolvulaceae & $\begin{array}{l}\text { Ipomoea bonariensis Hook. } \\
\text { Ipomoea cairica (L.) Sweet }\end{array}$ \\
\hline Dryopteridaceae & Rumohra adiantiformis (g.Forst) Ching * \\
\hline \multirow[t]{3}{*}{ Fabaceae } & Senna bicapsularis (L.) Roxb.* \\
\hline & Vigna candida (H.B.K.) Fawcett \& Rendle * \\
\hline & Vigna peduncularis (H.B.K.) Fawcett \& Rendle* \\
\hline Icacinaceae & Citronella cf. paniculata (Mart.) R.A. Howard* \\
\hline Melastomataceae & Tibouchina gracilis (Bonpl.) Cogn.* \\
\hline Moraceae & Ficus organensis cf. Miq. \\
\hline Passifloraceae & Passiflora edulis Sims \\
\hline Poaceae & Cortaderia selloana (Schult. \&Schult. F.) Asch. \& Graebn. \\
\hline Polemoniaceae & Phlox sp. * \\
\hline Solanaceae & Nicotiana sp. * \\
\hline
\end{tabular}

\section{AGRADECIMENTOS}

Agradecimentos ao Laboratório de Ecologia da Vegetação Costeira (Univali) e Laboratório de Biologia Vegetal (Univali), locais onde este estudo foi realizado. À Vanessa lara de Santana e Maíra Crispim Petres por auxiliarem em várias identificações, a Juliano Hillesheim por coletar parte do material botânico, à Mara Magenta por confirmar espécies de Asteraceae e a Anderson Alves-Araújo por auxiliar na atualização nomenclatural de Amaryllidaceae À Profa. Kátia R. S. Sauer Machado por revisar o abstract.

\section{REFERÊNCIAS}

Barroso, G.M. 1978. Sistemática de Angiospermas do Brasil. Vol.1, 2 e 3. Rio de Janeiro, LTC/EDUSP.

Bege, L.A.R. \& Pauli, B.T. 1988. As aves nas ilhas Moleques do Sul - Santa Catarina: Aspectos da ecologia, etologia e anilhamento de aves marinhas. Florianópolis, FATMA.

Branco, J.O. 2003a. Reprodução das aves marinhas nas ilhas costeiras de Santa Catarina, Brasil. Revista Brasileira de Zoologia, 20(4):619-623.

Branco, J.O. 2003b. Reprodução de Sterna hirundinacea Lesson e S. eurygnatha Saunders (Aves, Laridae), no litoral de Santa Catarina, Brasil. Revista Brasileira de Zoologia, 20(4):655-659.

Goldenber, A. \& Smith, L.B. 1975. Chave para as Famílias Espermatofíticas do Brasil. Itajaí, Separata de Flora llustrada Catarinense.

Instituto de Botânica. 1998. Técnicas de coleta, preservação e herborização de material botânico. coord. por Bononi \& Fidalgo. São Paulo, Série documentos. 1989.

Joly, A.B. 1998. Botânica: introdução à taxonomia vegetal. 12 ed. São Paulo, Cia. Editora Nacional.

Kissmann, K.G. 1991. Plantas Infestantes e Nocivas. Tomo 1.Basf, São Paulo.

Kissmann, K.G. \& Groth, D. 1992. Plantas Infestantes e Nocivas. Tomo 2. Basf, São Paulo.

Klein, R.M. 1979. Ecologia da Flora e Vegetação do Vale do Itajaí. Sellowia: 31(31):

Lombardo, A. 1984. Flora Montevidensis. Vol. 3. Montevidéu, Intendência Municipal.

Lorenzi, H. 1992. Árvores Brasileiras. Manual de Identificação e Cultivo de Plantas Arbóreas Nativas do Brasil. Vol. 1. Nova Odessa, Instituto Plantarum.

Lorenzi, H. 1998. Árvores Brasileiras. Manual de Identificação e Cultivo de Plantas Arbóreas Nativas do Brasil. Vol. 2. 2 ed. Nova Odessa, Instituto Plantarum.

Lorenzi, H. \& Souza, H.M. 2001. Plantas Ornamentais no Brasil. 3 ed, Nova Odessa, Instituto Plantarum. 
Rogalski \& Araújo:Florula da ilha de Moleques do Sul.

Miotto, S.T.S. 1999. Leguminosas do Rio Grande do Sul. Porto Alegre, Apostila do Curso de UFRGS, Dep. de Botânica.
Smith L.B. \& Smith R.C. 1971. Begoniáceas. In: Flora Ilustrada Catarinense. Itajaí: HBR. 128p.

Submetido: Outubro/2004 Revisado: Fevereiro/2005 Aceito: Agosto/2005 